\title{
Erratum: Imaging of Ampullary and Periampullary Conditions
}

\author{
Abhijit Sunnapwar ${ }^{1}$ Arpit Nagar $^{2}$ Rashmi Katre ${ }^{1}$ Lokesh Khanna ${ }^{1}$ Hari Prasad Sayana ${ }^{3}$ \\ ${ }^{1}$ Department of Radiology, University of Texas Health San Antonio, \\ San Antonio, Texas, United Sates \\ 2Department of Radiology, Ohio State University Wexner Medical \\ Center, Columbus, Ohio, United Sates \\ ${ }^{3}$ Department of Gastroenterology, University of Texas Health San

\begin{abstract}
Address for correspondence Abhijit Sunnapwar, MD, Department of Radiology, University of Texas Health San Antonio, 7703, Floyd Curl Drive, San Antonio, TX 78229, United Sates

(e-mail: sunnapwar@uthscsa.edu).
\end{abstract} Antonio, San Antonio, Texas, United Sates

J Gastrointestinal Abdominal Radiol ISGAR

ERRATUM

It has been brought to the publisher's attention that the affiliation details of the author "Abhijit Sunnapwar" were incorrectly set in the above article of the Journal of Gastrointestinal and Abdominal Radiology, published on May 5, 2021 (DOI: 10.1055/s-0041-1726663). The correct affiliation appears as above.

DOI https://doi.org/ 10.1055/s-0041-1731096 ISSN 2581-9933 (c)2021. Indian Society of Gastrointestinal and Abdominal Radiology This is an open access article published by Thieme under the terms of the Creative Commons Attribution-NonDerivative-NonCommercial-License, permitting copying and reproduction so long as the original work is given appropriate credit. Contents may not be used for commercial purposes, or adapted, remixed, transformed or built upon. (https://creativecommons.org/licenses/by-nc-nd/4.0/).

Thieme Medical and Scientific Publishers Pvt. Ltd. A-12, 2nd Floor, Sector 2, Noida-201301 UP, India 